\title{
High Hydrostatic Pressure Modification of Whey Protein Concentrate for Improved Body and Texture of Lowfat Ice Cream
}

\author{
S.-Y. Lim, B. G. Swanson, C. F. Ross, and S. Clark ${ }^{1}$ \\ Department of Food Science and Human Nutrition, Washington State University, Pullman 99164-6376
}

\begin{abstract}
Previous research demonstrated that application of high hydrostatic pressure (HHP), particularly at 300 $\mathrm{MPa}$ for $15 \mathrm{~min}$, can enhance foaming properties of whey protein concentrate (WPC). The purpose of this research was to determine the practical impact of HHPtreated WPC on the body and texture of lowfat ice cream. Washington State University (WSU)-WPC was produced by ultrafiltration of fresh separated whey received from the WSU creamery. Commercial whey protein concentrate 35 (WPC 35) powder was reconstituted to equivalent total solids as WSU-WPC (8.23\%). Three batches of lowfat ice cream mix were produced to contain WSU-WPC without HHP, WSU-WPC with HHP (300 MPa for $15 \mathrm{~min}$ ), and WPC 35 without HHP. All lowfat ice cream mixes contained $10 \%$ WSU-WPC or WPC 35. Overrun and foam stability of ice cream mixes were determined after whipping for $15 \mathrm{~min}$. Ice creams were produced using standard ice cream ingredients and processing. The hardness of ice creams was determined with a TA-XT2 texture analyzer. Sensory evaluation by balanced reference duo-trio test was carried out using 52 volunteers. The ice cream mix containing HHP-treated WSU-WPC exhibited the greatest overrun and foam stability, confirming the effect of HHP on foaming properties of whey proteins in a complex system. Ice cream containing HHP-treated WSU-WPC exhibited significantly greater hardness than ice cream produced with untreated WSU-WPC or WPC 35. Panelists were able to distinguish between ice cream containing HHP-treated WSU-WPC and ice cream containing untreated WPC 35. Improvements of overrun and foam stability were observed when HHP-treated whey protein was used at a concentration as low as $10 \%(\mathrm{wt} / \mathrm{wt}$ ) in ice cream mix. The impact of HHP on the functional properties of whey proteins was more pronounced than the impact on sensory properties.
\end{abstract}

Received May 25, 2007.

Accepted December 21, 2007.

${ }^{1}$ Corresponding author: stephclark@wsu.edu
Key words: whey protein concentrate, high hydrostatic pressure, lowfat ice cream, foaming property

\section{INTRODUCTION}

Fats interact with other ingredients to provide texture, mouthfeel, creaminess, and overall sensation of lubricity of a food (Giese, 1996; Akoh, 1998). Because fat provides a desirable texture, mouthfeel, and flavor to most foods, many consumers are reluctant to switch to a lowfat diet (Drewnowski, 1992; Guinard et al., 1996). However, consumers may be satisfied consuming a lowfat diet if the sensory properties of lowfat foods are improved, so the development of lowfat foods with body, texture, and mouthfeel of full-fat foods is justified. One of the goals in modifying ice cream formulations is to produce an ice cream with a desirable texture; enhancement of texture will only occur through improvement in the ice cream's physical structure (Stanley et al., 1996).

Milk fat is an important determinant of texture and body of ice cream. Textural creaminess is a highly desirable sensory attribute that is contributed to ice cream by milk fat but is difficult to obtain with fat replacers (Ohmes et al., 1998). In recent years, manufacturers have reduced the amount of fat in ice cream and replaced fat with carbohydrates or proteins (Giese, 1996). Reduced fat ice creams with carbohydrate-based fat replacers are commonly perceived as weak in body or exhibiting a gummy texture, both reducing the satisfaction of consumers (Ohmes et al., 1998).

Fat replacers derived from whey protein exhibit distinctive properties that promote functional performance in food systems similar to the functionality of fat globules (Ohmes et al., 1998). Three fat replacers are made from whey protein. The manufacturers identify Dairy Lo (Cultor Food Science, Ardsley, NY) and Prolo 11 (Kerry Ingredients, Beloit, WI) as denatured whey protein, and describe Simplesse 100 (The Nutrasweet Kelco Co., San Diego, CA) as microparticulated whey protein (Ohmes et al., 1998). Heat denaturation of whey protein molecules results in unfolding and aggregation. The degree of protein unfolding and aggregation also affects functional properties of the final product (deWit 
et al., 1996). The functional behavior of processed whey in food systems, especially in foams and emulsions, may not meet consumer expectations if heated at temperatures greater than $70^{\circ} \mathrm{C}$, which is traditionally used to concentrate and dry whey protein concentrate (WPC) powder (Richert et al., 1974). Several studies concluded that heating of WPC at moderate temperatures (between 40 and $50^{\circ} \mathrm{C}$ ) improves its foaming properties, whereas heat treatment at greater than $70^{\circ} \mathrm{C}$ results in impairment of foaming properties by irreversible whey protein denaturation and aggregation (DeVilbiss et al., 1974; Richert et al., 1974; deWit and Klarenbeek, 1984). The high temperature of spray drying tends to result in considerable decreases in WPC functionality.

Partial denaturation, instead of irreversible denaturation, is suggested as a technique for improvement of whey protein functionality. High hydrostatic pressure (HHP) is an alternative to conventional thermal processing and is considered one of the most promising new methods to improve functional properties of whey proteins. Whey proteins treated with HHP exhibit potential to improve textural properties of dairy products (Messens et al., 1997; Datta and Deeth, 1999; Needs et al., 2000; Lim et al., 2008). High hydrostatic pressure treatment in the range of 100 to $1,000 \mathrm{MPa}$ was suggested as an alternative treatment for partial denaturation of whey proteins, with improved effects on the quality of dairy products (Cheftel, 1992; Mussa and Ramaswamy, 1997). The use of HHP exhibits a disruptive effect on intramolecular hydrophobic and electrostatic interactions in whey protein molecules, resulting from an increase in protein surface hydrophobicity. The surface hydrophobicity can improve interfacial properties and foaming properties of HHP-treated $\beta$-LG and whey protein isolate (WPI) (Galazka et al., 1997; Ibanoglu and Karatas, 2001). Improvement of foaming properties may help strengthen body and provide a smooth texture to lowfat ice cream when pressuretreated WPC is utilized as a fat replacer. Improvements are expected because ice creams containing greater amounts of air showed a thinner unfrozen phase dispersed around air bubbles, which results in a reduction of crystal size (Flores and Goff, 1999). The strong foam structure may reduce the probability of collision between crystals, resulting in a smooth ice cream texture (Flores and Goff, 1999).

Fresh whey [Washington State University-whey protein concentrate (WSU-WPC)] may demonstrate better fat replacer characteristics and foaming properties in dairy products than spray-dried whey [whey protein concentrate 35 (WPC 35)], because fresh whey contains less heat-denatured and aggregated proteins than did WPC powder. Direct use of fluid whey instead of a powder as a fat replacer is a relatively innovative process whereby whey is concentrated by UF without exposing the WPC to temperatures greater than $70^{\circ} \mathrm{C}$. Ibanoglu and Karatas (2001) reported that an optimum high pressure treatment is $300 \mathrm{MPa}$ for $15 \mathrm{~min}$, which provided maximum foam stability of WPI at $\mathrm{pH}$ 7. High hydrostatic pressure treatment enhances foaming properties of UF WPC, particularly at $300 \mathrm{MPa}$ for $15 \mathrm{~min}$ (Lim et al., 2008). Thus, HHP-treated fresh WPC may improve body and texture of lowfat ice cream and justify use of a fat replacer. The objective of this research was to investigate instrumental and sensory differences of lowfat ice cream made with WSU-WPC, WPC 35, and HHP-treated WSU-WPC.

\section{MATERIALS AND METHODS}

\section{Preparation of Whey}

Sweet whey from Cheddar cheese making at the WSU Creamery (Pullman, WA) was pasteurized, ultrafiltered, and diluted according to Lim et al. (2008). The WSU-WPC was concentrated to about $8.23 \%$ total solids, which contributed to $3.02 \%$ protein content (Lim et al., 2008). The WPC 35 powder from Foremost Farms (Baraboo, WI) was reconstituted according to Lim et al. (2008) to contain $8.23 \%$ total solids and $3.06 \%$ protein. The WSU-WPC was pasteurized according to Lim et al. (2008). Solutions of reconstituted WSU-WPC were treated at $300 \mathrm{MPa}$ for $15 \mathrm{~min}$ holding time at an initial temperature of $25^{\circ} \mathrm{C}$, and temperature inside the chamber did not exceed $40.5^{\circ} \mathrm{C}$ (Lim et al., 2008). A bag containing about $500 \mathrm{~mL}$ of WSU-WPC solution was put in the chamber of the HHP for 1 cycle. After exposure to high pressure, HHP-treated WSU-WPC samples were stored at $4^{\circ} \mathrm{C}$ until production of lowfat ice cream mix. Untreated WSU-WPC and WPC 35 were reconstituted to $8.23 \%$ total solids with pasteurized deionized water and incorporated into mix formulations.

\section{Manufacture of Lowfat Ice Cream Mix}

The ice cream mix contained $4.6 \%$ milk fat and $11.1 \%$ serum solids contributed by whole milk (3.7\% fat, WSU Creamery), cream (40\% fat, Meadow Gold Dairies, TX), skim milk (Meadow Gold Dairies), NDM (Darigold, Seattle, WA), and extra WSU-WPC (WSU Creamery) or WPC 35 (Foremost Farms); 14.6\% sucrose (The Amalgamated Sugar Company LLC, Boise, ID); 3.4\% 42 dextrose-equivalent corn syrup solids sweetener (Cargill, Cedar Rapids, IA); 4.1\% Maltrin 100 bulking agent (Grain Processing Corporation, Muscatine, IA); and $0.7 \%$ stabilizer and emulsifier mix (Grinsted Ice pro 200554, Danisco, New Century, KS). The mix formulations are presented in Table 1 . Three batches of lowfat ice cream mix contained $38 \%$ TS and were produced at 
Table 1. Basic lowfat ice cream mix formulations before vanilla flavor addition

\begin{tabular}{lclccc}
\hline Ingredient & $\begin{array}{c}\text { Weight } \\
(\%)\end{array}$ & $\begin{array}{c}\text { Fat } \\
(\mathrm{kg})\end{array}$ & $\begin{array}{c}\mathrm{MSNF}^{1} \\
(\mathrm{~kg})\end{array}$ & $\begin{array}{c}\text { Sugar } \\
(\mathrm{kg})\end{array}$ & $\begin{array}{c}\text { Total } \\
\text { solids }(\mathrm{kg})\end{array}$ \\
\hline Cream & 6.90 & 2.78 & 0.41 & 0.0 & 3.17 \\
Skim milk & 8.40 & 0.0 & 0.8 & 0.0 & 0.81 \\
Whole milk & 47.00 & 1.65 & 4.28 & 0.0 & 5.92 \\
NDM & 5.00 & 0.05 & 4.8 & 0.0 & 4.85 \\
WSU-WPC & & & & & \\
or WPC 35 ${ }^{3}$ solutions & 10.00 & 0.03 & 0.8 & 0.0 & 0.82 \\
Maltrin 500/100 & 4.10 & 0.0 & 0.0 & 0.14 & 3.88 \\
Sugar & 14.55 & 0.0 & 0.0 & 14.55 & 14.55 \\
42\% CSS & 3.35 & 0.0 & 0.0 & 3.25 & 3.25 \\
Stabilizer/emulsifier & 0.70 & 0.12 & 0.0 & 0.08 & 0.69 \\
Total & 100.00 & 4.61 & 11.1 & 18.0 & 37.94 \\
\hline
\end{tabular}

${ }^{1}$ Milk solids nonfat.

${ }^{2}$ Washington State University (WSU) whey protein concentrate (WPC).

${ }^{3}$ Commercial WPC 35 .

${ }^{4}$ Corn syrup solids.

the WSU Creamery. Diacetyl flavor (Sigma Aldrich, Louis, MO), $0.0002 \%$ (vol/vol), was added into WSUWPC or WPC 35 before WSU-WPC or WPC 35 was incorporated into the mix. Mixes were equivalent except that mix A contained untreated WSU-WPC; mix B contained HHP-treated WSU-WPC; and mix C contained untreated WPC 35 . The WPC 35 was pasteurized at a temperature greater than $75^{\circ} \mathrm{C}$ for at least $15 \mathrm{~s}$ followed by spray-drying at a temperature less than $100^{\circ} \mathrm{C}$.

\section{Manufacture of Lowfat Ice Cream}

Three batches of ice cream mix were homogenized (Lab 60, Gaulin GMBH, Lubeck, Germany) at 3,447 $\mathrm{kPa}$ in the second stage and $17,237 \mathrm{kPa}$ in the first stage, and pasteurized using a universal pilot plant system (Processing Machinery and Supply Co., Philadelphia, PA) in a continuous plate heat exchanger at $82^{\circ} \mathrm{C}$ for $15 \mathrm{~s}$ holding time. To avoid variation in mixes, the 3 batches were made in succession on the same day. Before freezing, each mix was aged for $12 \mathrm{~h}$ at $4^{\circ} \mathrm{C}$. Four-fold vanilla flavor (Santa Fe Distribution, Dayton, WA) was added at a proportion of $83 \mathrm{~mL}$ to $43.6 \mathrm{~kg}$ of ice cream mix before freezing. The mixes were frozen using a continuous freezer (Technogel 100, Bergumo, Italy) for a desired overrun of $60 \%$. After freezing, ice cream was collected into 1-pint $(473 \mathrm{~mL})$ containers and placed into a hardening freezer at $-30^{\circ} \mathrm{C}$ for storage.

\section{Foaming Properties of Lowfat Ice Cream Mix}

Mixes were tested for overrun and foam stability after whipping in a household-type mixer (Kitchen Aid Mixer) at cold temperature $\left(4 \pm 2^{\circ} \mathrm{C}\right.$ ), in triplicate (Lim et al., 2008). During foam formation, the mixer was stopped at 5 -min intervals (e.g., 5,10 , or $15 \mathrm{~min}$ ) to determine overrun, and the mixer head was carefully lifted to minimize destruction of the foam for overrun determination (Phillips et al., 1990). A plastic whipping bowl was modified to test foam stability (Lim et al., 2008). The time to attain $50 \%$ drainage was used as an index of foam stability (Phillips et al., 1990).

\section{Rheological Properties of Lowfat Ice Cream Mix}

Rheological properties were determined in triplicate using a Physica rheometer using concentric cylinders (CC27; Model 320, Paar Physica USA Inc., Glen Allen, VA). The determinations were controlled to maintain the temperature at $10^{\circ} \mathrm{C}$ by circulating water from an external water bath through a jacket surrounding the rotor and cup assembly. Shear rates (with a logarithmic scale increase at every $10 \mathrm{~s}$ ) were programmed to upward $\left(0.1\right.$ to $\left.300 \mathrm{~s}^{-1}\right)$ and downward (300 to $0.1 \mathrm{~s}^{-1}$ ) curves to obtain shear stress and viscosity data. The rheological parameters were obtained at shear rates of upward and downward curves using Origin Software version 5.0 (Northampton, MA).

\section{Hardness Determination of Lowfat Ice Cream}

Ice cream that retained the required overrun $(60 \pm$ $5 \%$ ) was used for triplicate analyses of hardness. Hardness determinations were obtained at room temperature $\left(25 \pm 2^{\circ} \mathrm{C}\right)$ using a texture analyzer (TA-XT2, Stable MicroSystems Ltd., White Salmon, WA) equipped with a $2.5-\mathrm{cm}$-diameter acrylic cylindrical probe (Roland et al., 1999). The ice cream, hardened at $-30^{\circ} \mathrm{C}$, was cut to fill a small cylindrical cup ( $4.5 \mathrm{~cm}$ in diameter) to a depth of $30 \mathrm{~mm}$ and tempered overnight to $-15^{\circ} \mathrm{C}$ before analysis. The penetration speed of the probe was $2 \mathrm{~mm} /$ $\mathrm{s}$ to a distance of $20 \mathrm{~mm}$ (Guinard et al., 1996). 


\section{Sensory Evaluation}

Fifty-two students and employees of WSU evaluated differences of lowfat vanilla ice cream in private booths using Compusense Five software (release 4.6, Guelph, Canada). A randomized incomplete block design was used for this evaluation. The balanced reference duotrio test was used to determine the ability of consumers to distinguish differences between ice cream formulations. The cups containing 1 scoop of ice cream (about $30 \mathrm{~g}$ ) were labeled with random 3-digit codes generated by computer software. Water was provided for palate cleansing when panelists were in the booths. The order of presentation of the ice creams was randomized across panelists to prevent bias effects. Panelists were also asked to comment on the flavor and texture of the ice creams provided in each flight.

\section{Statistical Analysis}

The 1-way ANOVA test for significant effects of treatments and physical tests of ice cream mixes and ice creams was determined using the GLM procedure (PROC GLM) in SAS (SAS Institute, 1999). Main effect differences were considered significant at the $P \leq 0.05$ level. Mean separations were determined by Tukey's procedure for multiple comparisons. The duo-trio test determined whether panelists perceived a difference between ice creams. Compusense Five software conducted the statistical analysis to compare the number of correct judgments to the probability of chance occurrence to establish significance at 0.05 probability level $(P \leq 0.05$ level $)$.

\section{RESULTS AND DISCUSSION}

\section{Foaming Properties of Lowfat Ice Cream Mix}

As noted in experiments with WSU-WPC (Lim et al., 2008), the ice cream mix containing HHP-treated WSUWPC exhibited the greatest overrun (Figure 1) and foam stability of selected treatments (Figure 2). The ice cream mix containing HHP-treated WSU-WPC exhibited significantly larger overrun than the ice cream mix containing untreated WPC 35 until 10 min whipping time (Figure $1, P \leq 0.05$ ) and the 3 ice cream mixes exhibited significantly different foam stability values (Figure 2, $P \leq 0.05$ ). Observation of larger overrun and stronger foam stability confirmed the effect of HHP treatment of whey proteins on subsequent foaming properties exhibited by ice cream mix even when used at a concentration as low as $10 \%$ in a formulation (Table 1). The ice cream mix containing untreated WPC 35 exhibited the smallest overrun and weakest foam stability. The poor functionality of untreated WPC 35 pow-

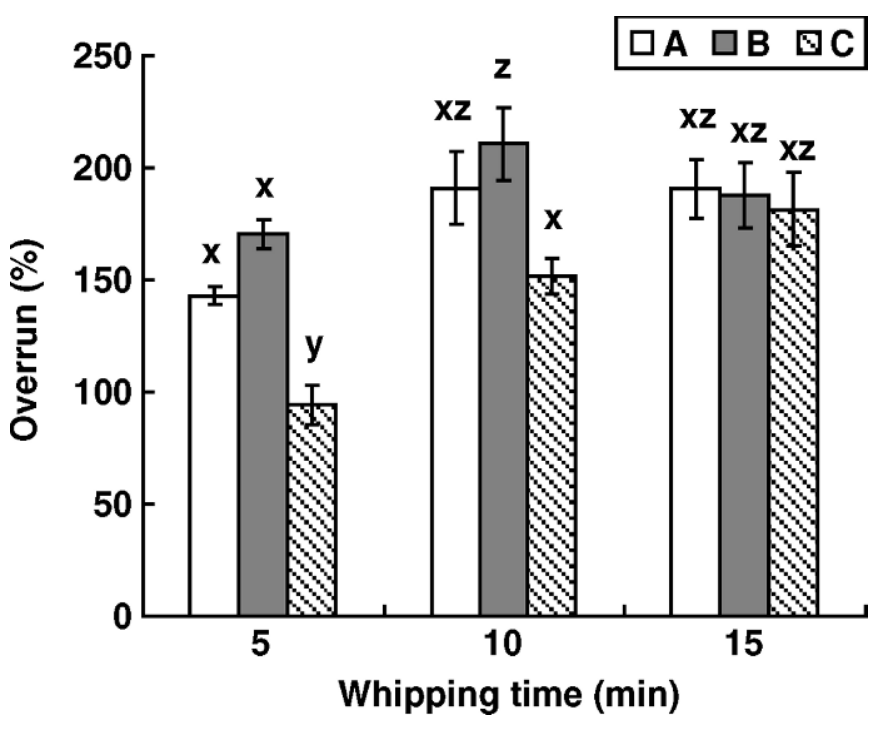

Figure 1. Whipping time and overrun of lowfat ice cream mix [A = untreated Washington State University whey protein concentrate (WSU-WPC); B = high hydrostatic pressure-treated WSU-WPC; C = untreated WPC 35]. ${ }^{\mathrm{x}-\mathrm{z}}$ Different letters indicate that significant differences exist within whipping times; $P \leq 0.05$; vertical lines indicate SD.

der is attributed to denaturation of proteins resulting from heat treatment, evaporation, and drying. Zhu and Damodaran (1994) reported that heating of WPI for 1 min at $70^{\circ} \mathrm{C}$ resulted in an increase of foaming properties compared with the foaming properties of unheated WPI. However, foaming properties of WPI heating for

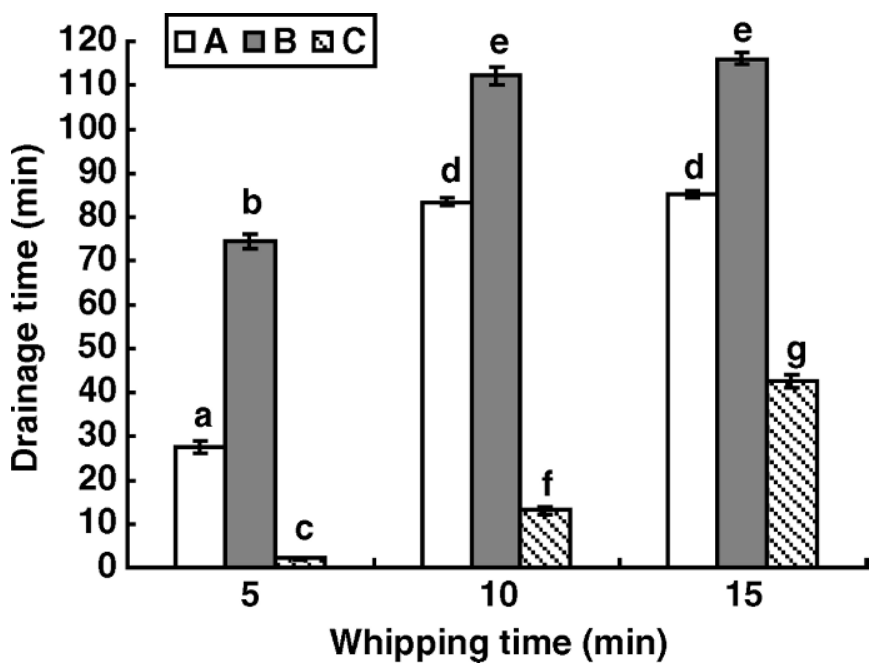

Figure 2. Whipping time and foam stability of lowfat ice cream $\operatorname{mix}(\mathrm{A}=$ untreated Washington State University whey protein concentrate (WSU-WPC); B = high hydrostatic pressure-treated WSUWPC; $\mathrm{C}=$ untreated WPC 35). ${ }^{\mathrm{a}-\mathrm{g}}$ Different letters indicate significant differences exist within whipping times; $P \leq 0.05$; vertical lines indicate SD. 
5 min at $90^{\circ} \mathrm{C}$ exhibited a dramatic decrease compared with the foaming properties of native WPI (Zhu and Damodaran, 1994). Increases in the temperature and time of heating progressively decrease the foaming properties. Experiments with foaming stability of ice cream mix demonstrate that heat-induced changes in the physicochemical properties of WPI decrease foaming properties, so the decrease in overrun and foam stability for ice cream mix containing untreated WPC 35 is expected. The overrun and foam stability of the ice cream mix containing untreated WSU-WPC were intermediate between ice cream mixes containing HHPtreated WSU-WPC and untreated WPC 35, attributed to the limited exposure to heat (proteins fully denatured) or high pressure (proteins partially denatured). The native state (folded) of whey proteins may also restrict hydrophobic interactions necessary for strong foam stability (Morr and Ha, 1993).

\section{Rheological Properties of Lowfat Ice Cream Mix}

Ice cream mix viscosity is an important parameter in determining flow behavior. Many factors contribute to the viscosity of ice cream mix. Hydrocolloid constituents in ice cream mix interact with water and other solutes and play an important role in ice cream mix viscosity. The viscosity is critical for determining flow behavior in the holding tube of a continuous pasteurizer, the intermediate unit operation in the processing of ice cream mix (Goff et al., 1994). The power law model was used to characterize the viscosity of the experimental lowfat ice cream mixes for typical shear rates: $\sigma=$ $\mathrm{K} \dot{r}^{\mathrm{n}}$, where $\sigma=$ shear stress $(\mathrm{Pa}), \dot{r}=$ shear rate (per second), $\mathrm{K}=$ consistency coefficient $\left(\mathrm{Pa} \cdot \mathrm{s}^{\mathrm{n}}\right)$, and $\mathrm{n}=$ flow behavior index (dimensionless; Goff et al., 1994). The $\mathrm{K}$ and $\mathrm{n}$ values were calculated by the power law model (Goff et al., 1994; Penna et al., 2006). Large K values and small $\mathrm{n}$ values predict more-viscous ice cream mixes.

Figures 3 and 4 indicate the apparent viscosity of ice cream mixes was decreased by an increase in shear rate, although experimental observations were made at small shear rates (between 0.1 and $10 \mathrm{~s}^{-1}$ ). Instrumental viscosity for lowfat ice cream mix containing HHP-treated WSU-WPC was significantly greater than the viscosity for lowfat ice cream mix containing untreated WSU-WPC or WPC 35 (Figure 3 and Table 2, $P \leq 0.05$ ). Previous research concluded that the viscosities of ice cream mixes made by fortifying with UF whey were greater than the viscosities of mixes made by fortifying with WPC powder (Naidu et al., 1986; Lee and White, 1991). Ice cream mix containing fresh WSUWPC exhibited greater viscosity than ice cream mix containing dried WPC 35 in the present work. The fact

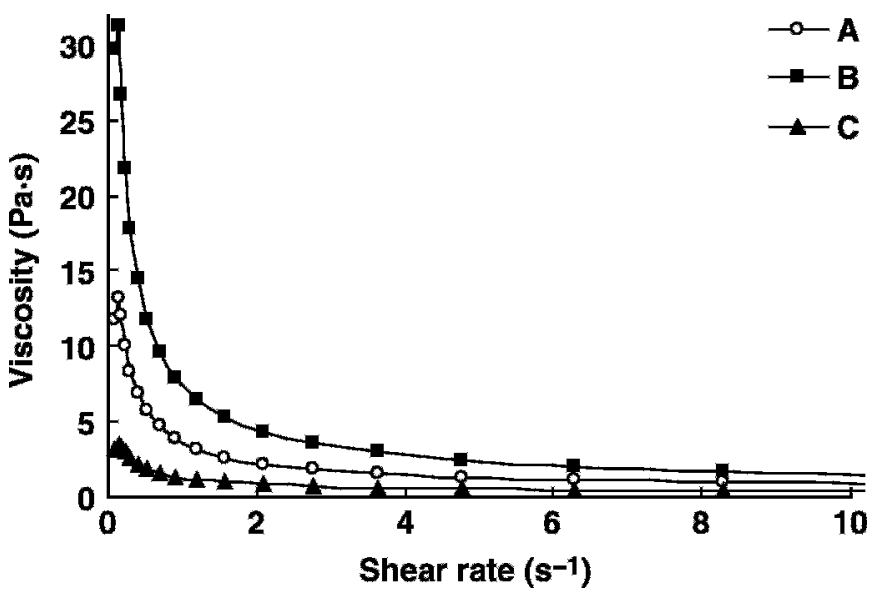

Figure 3. Apparent viscosity at $10^{\circ} \mathrm{C}$ on shear rate $(0.1$ to 10 $\mathrm{s}^{-1}$, upward rate) of lowfat ice cream mix formulation [A = untreated Washington State University whey protein concentrate (WSU-WPC); $\mathrm{B}=$ high hydrostatic pressure-treated WSU-WPC; $\mathrm{C}=$ untreated WPC 35].

that TS, fat, and protein concentrations were held constant in ice cream mix demonstrates that protein structure may influence the viscosity of the ice cream mixes.

Initially, nonlinear regression based on the shear stress and shear rate data for triplicates was used to estimate $\mathrm{n}$ and $\mathrm{K}$ for each ice cream mix. The shear rate and shear stress of lowfat ice cream mixes in upward rate $\left(0.1\right.$ to $\left.300 \mathrm{~s}^{-1}\right)$ and downward rate (300 to $0.1 \mathrm{~s}^{-1}$ ) determined using the power law model is presented in Table 2. Lowfat ice cream mix can be characterized as a non-Newtonian fluid with thixotropic flow

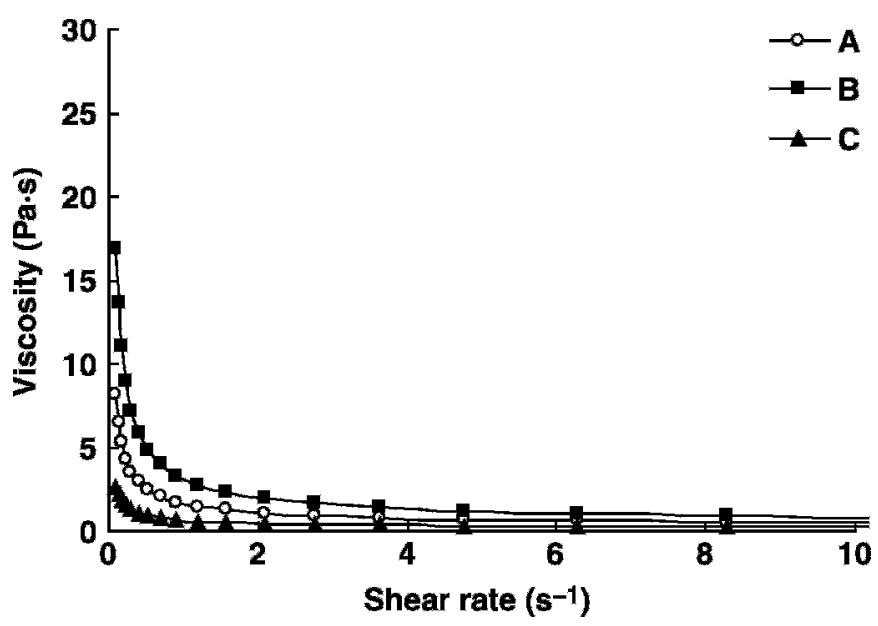

Figure 4. Apparent viscosity at $10^{\circ} \mathrm{C}$ on shear rate $\left(10\right.$ to $0.1 \mathrm{~s}^{-1}$ downward rate) of lowfat ice cream mix formulation $[\mathrm{A}=$ untreated Washington State University whey protein concentrate (WSU-WPC); $\mathrm{B}=$ high hydrostatic pressure-treated WSU-WPC; C = untreated WPC 35]. 
Table 2. Flow parameters ${ }^{1}$ of lowfat ice cream mix using the power law model (shear rate ranged from 0.1 to $300 \mathrm{~s}^{-1}$ and determinations were made at $10^{\circ} \mathrm{C}$ )

\begin{tabular}{lccccccc}
\hline & \multicolumn{3}{c}{ Upward rate $^{3}$} & & \multicolumn{3}{c}{ Downward rate $^{3}$} \\
\cline { 2 - 4 } \cline { 6 - 7 } Mix $^{2}$ & $\mathrm{~K}\left(\mathrm{~Pa} \cdot \mathrm{s}^{\mathrm{n}}\right)$ & $\mathrm{n}$ & $\mathrm{R}^{2}$ & & $\mathrm{~K}\left(\mathrm{~Pa} \cdot \mathrm{s}^{\mathrm{n}}\right)$ & $\mathrm{n}$ & $\mathrm{R}^{2}$ \\
\hline $\mathrm{A}$ & $2.372^{\mathrm{a}}$ & $0.546^{\mathrm{a}}$ & 0.9968 & & $0.815^{\mathrm{a}}$ & $0.731^{\mathrm{a}}$ & 0.9992 \\
$\mathrm{~B}$ & $5.123^{\mathrm{b}}$ & $0.485^{\mathrm{b}}$ & 0.9947 & & $1.377^{\mathrm{b}}$ & $0.712^{\mathrm{a}}$ & 0.9985 \\
$\mathrm{C}$ & $0.846^{\mathrm{c}}$ & $0.643^{\mathrm{c}}$ & 0.9993 & & $0.372^{\mathrm{c}}$ & $0.784^{\mathrm{b}}$ & 0.9998 \\
\hline
\end{tabular}

${ }^{\mathrm{a}-c}$ Values for each parameter with the same letter in the same row do not differ $(\alpha=0.05)$.

${ }^{1} \mathrm{~K}=$ consistency coefficient; $\mathrm{n}$ = flow behavior index (dimensionless); $\mathrm{R}^{2}=$ determination coefficient.

${ }^{2} \mathrm{~A}=$ untreated Washington State University whey protein concentrate (WSU-WPC); B = high hydrostatic pressure-treated WSU-WPC; C = untreated WPC 35.

${ }^{3} \mathrm{Upward}$ rate $\left(0.1\right.$ to $\left.300 \mathrm{~s}^{-1}\right)$ and downward rate (300 to $\left.0.1 \mathrm{~s}^{-1}\right)$ of shear rate change.

behavior resulting from the structural breakdown of a fluid during the shearing cycle (Goff et al., 1994). Thixotropic flow behavior is identified by the differences between the upward and downward rate of the shear rate/stress relationship when applying the power law model. Using the power law model to describe the apparent viscosity as a function of the shear rate raised to an exponent of $n$, a solution with an $n$ value less than 1.0 exhibits decreasing apparent viscosity as the shear rate increases, referred to as a non-Newtonian fluid with pseudoplastic behavior (Goff et al., 1994).

The differences in rheological properties of lowfat ice cream mixes (Table 2) are attributed to the differences in the structure of the whey proteins. The rheological properties of ice cream mixes are often described as pseudoplastic because the viscosity becomes thinner with increased shear rate and $\mathrm{n}$ values are less than 1.0, defining the characteristic of non-Newtonian pseudoplastic behavior (Cottrell et al., 1980). The $n$ values are an indication of the departure from Newtonian behavior for a pseudoplastic fluid. When $\mathrm{n}$ value equals 1.0 , the fluid is Newtonian, and a smaller $\mathrm{n}$ value represents a greater departure from Newtonian behavior (Cottrell et al., 1980). Flow behavior index (n) values ranging from 0.48 to 0.94 are reported for ice cream mixes (Cottrell et al., 1980). Smith et al. (1984) reported $\mathrm{n}$ values for full-fat ice cream mix ranging from 0.48 to 0.55 . In the present study, the $\mathrm{n}$ values (Table 2) of lowfat ice cream mixes containing HHP-treated WSUWPC (0.485) and untreated WSU-WPC (0.546) were included in $\mathrm{n}$ values ranges of full-fat ice cream mix (0.48 to 0.55) reported by Smith et al. (1984). The results of $n$ values in lowfat ice cream mixes containing HHPtreated WSU-WPC or untreated WSU-WPC may reflect shear thinning of partially denatured or native proteins rather than fat globules. In contrast, the $\mathrm{n}$ values for lowfat ice cream mix containing untreated WPC 35 $(0.643$, Table 2$)$ were not in the $\mathrm{n}$ value range of fullfat ice cream mix (0.48 to 0.55 ) reported by Smith et al. (1984), suggesting that the mix containing untreated
WPC 35 exhibited thinner viscosity than the viscosity of full-fat ice cream mix. The deviation of the $\mathrm{n}$ values of ice cream mix containing WPC 35 from the $\mathrm{n}$ value range of full-fat ice cream mix is attributed to possible denaturation of the whey proteins.

Consistency coefficients (K values) were also obtained from the power law model. Lowfat ice cream mix containing untreated WPC 35 exhibited significantly lower $\mathrm{K}$ values than lowfat ice cream mix containing HHPtreated WSU-WPC (Table $2, P \leq 0.05$ ). The $\mathrm{K}$ values of lowfat ice cream mix containing HHP-treated WSUWPC (5.123) were significantly greater than the ice cream mix containing untreated WSU-WPC (2.372) and WPC $35(0.846)$ in upward rate (Table $2, P \leq 0.05$ ). Aime et al. (2001) also reported that the $K$ values of full-fat ice cream (0.547) were greater than $\mathrm{K}$ values of fatfree ice cream (0.073). The $\mathrm{K}$ values were positively correlated with apparent viscosity and sensory viscosity data, indicating that lowfat and fat-free ice cream mixes were not as viscous as full-fat ice cream mixes (Aime et al., 2001). Considering apparent viscosity, $\mathrm{K}$ values, and $\mathrm{n}$ values, lowfat ice cream mix containing HHPtreated WSU-WPC in the present study was more viscous than traditional lowfat ice cream mix containing untreated WPC 35. The ice cream mixes containing untreated WSU-WPC exhibited an intermediate value in rheological properties and apparent viscosity between ice cream mixes containing untreated WPC 35 and HHP-treated WSU-WPC. The explanation for the results of rheological properties mirrors that of foaming properties: extent of protein denaturation (native protein, partial denaturation, or complete denaturation) dictated rheological properties.

\section{Hardness Determination of Lowfat Ice Cream}

Hardness of ice cream is the resistance of ice cream to deformation when a standardized external force is applied. Acceptable hardness of lowfat ice cream will maintain resistance to compression in the mouth when 
1314

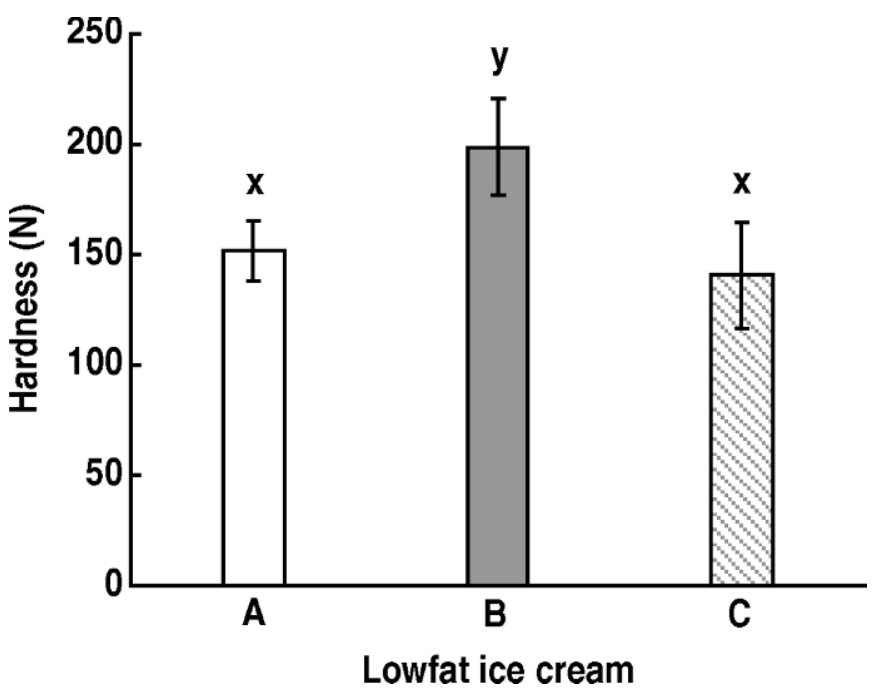

Figure 5. Whey protein concentrate (WPC) treatment $(\mathrm{A}=$ untreated Washington State University WPC; B = high hydrostatic pressure-treated Washington State University WPC; C = untreated WPC 35) and the hardness of lowfat ice cream. ${ }^{\mathrm{x}, \mathrm{y}}$ Different letters indicate significant differences exist; $P \leq 0.05$.

ice cream is ingested. Ice cream containing HHPtreated WSU-WPC exhibited the greatest hardness and significantly greater hardness $(P \leq 0.05)$ than ice cream containing untreated WSU-WPC or WPC 35 (Figure 5). Pridiville et al. (1999) tested hardness of ice cream with 4 selected fat contents and reported that full-fat ice cream was significantly harder than reduced-fat ice creams. Moreover, lowfat vanilla ice cream made from ice cream mix containing freeze-concentrated nonfat milk solids (NMS) was smoother in texture, firmer in body, and slower to melt than lowfat ice cream of equivalent composition but made from heat-concentrated skim milk or NMS because the proteins in the heatconcentrated NMS were denatured more during manufacture than the proteins in the freeze-concentrated NMS (Garcia et al., 1995). Because partially denatured proteins often exhibit substantial hydrophobic interactions, the structure of the continuous phase is strengthened, resulting in increased amounts of bound water (Harper and Mangino, 2007). Proteins contain AA that have polar side chains, but that do not have a charge. The nonionized polar AA in proteins typically have 2 water molecules strongly associated with them. Water associated with hydrophobic groups is highly ordered and has been termed hydrophobic hydration water. If the protein molecule is unfolded, hydrophobic groups may make better contact with the aqueous phase. The hydrophobic groups tend to cause an increase in order of water molecules near them (Harper and Mangino, 2007). Therefore, hydrophobicity may increase hardness in ice cream. Ice creams made from dried WPC 35
Table 3. Lowfat ice cream sensory evaluation $(n=52)$ statistical analysis using Compusense Five, release 4.6.

\begin{tabular}{lccc}
\hline & \multicolumn{3}{c}{ Ice creams (test) $^{1}$} \\
\cline { 2 - 4 } Evaluation & A vs. B & B vs. C & A vs. C \\
\hline Same (correct guess) & 22 & 37 & 25 \\
Different (wrong guess) & 30 & 15 & 27 \\
Confidence & 0.106 & 0.998 & 0.339 \\
Significance (P-value) & 0.894 & 0.002 & 0.661 \\
& $(P>0.05)$ & $(P \leq 0.05)$ & $(P>0.05)$ \\
\hline
\end{tabular}

${ }^{1} \mathrm{~A}=$ untreated WSU-WPC; $\mathrm{B}=$ high hydrostatic pressure-treated WSU-WPC; C = untreated WPC 35 .

were significantly softer $(P \leq 0.05)$ than ice creams made from HHP-treated WSU-WPC. This may be attributed to heat denaturation of the whey proteins during the production of WPC 35 powder, resulting in less hydrophobic interactions. Use of HHP-treated WSU-WPC as a fat replacer in lowfat ice cream may be effective in mimicking the hardness of full-fat ice cream.

\section{Sensory Analysis}

Texture is an important factor of food because texture influences the acceptability of food (Yilsay et al., 2006). The resistance of ice cream to the mechanical forces imparted by the tongue, upper palate, and teeth is detected, and the overall perception of ice cream texture is a part of sensory acceptance (Yilsay et al., 2006). Panelists were not able to distinguish between ice creams containing HHP-treated WSU-WPC and untreated WSU-WPC or between ice creams containing untreated WSU-WPC and untreated WPC $35(P>0.05$, Table 3). However, panelists were able to distinguish $(P \leq 0.05)$ between ice cream containing HHP-treated WSU-WPC and ice cream containing untreated WPC 35 (Table 3). Although WPC comprised only $10 \%$ of the entire formulation (a contribution of $0.82 \%$ TS and $0.3 \%$ protein), consumers were able to recognize differences between the extreme treatments: ice cream containing reconstituted commercial WPC 35 or HHP-treated WSU-WPC. The distinction by panelists reflects differences in the initial processing (fresh or spray dried) compared with HHP treatments because significant differences were not noted between ice creams containing untreated and HHP-treated WSU-WPC.

The sensory evaluation results are supported by the physical results. To review, the ice cream mix containing HHP-treated WSU-WPC exhibited significantly larger overrun than the ice cream mix containing untreated WPC 35 until 10 min whipping time and panelists noted differences between ice creams containing HHP-treated WSU-WPC and untreated WPC 35. The ice cream mix containing HHP-treated WSU-WPC was 
not significantly different in overrun from the ice cream mix containing untreated WSU-WPC, and panelists could not distinguish between the ice creams. Similarly, the ice cream mix containing untreated WSU-WPC was not significantly different in overrun from the ice cream mix containing untreated WPC 35 and panelists could not distinguish between the ice creams (Figure 1, Table 3 ). The results of sensory evaluations suggest that panelists may recognize overrun differences rather than foam stability differences of ice cream mix. Foam stability and viscosity of ice cream mix exhibited equivalent patterns to overrun and sensory evaluation, but significant differences were realized among the 3 ice cream mixes for foam stability and viscosity. Product development research takes advantage of HHP-induced modifications of whey proteins to utilize HHP treatment of fresh WPC not only in ice cream, but also in other food systems requiring stable foaming properties, including whipping cream. The sensory analysis demonstrates that significant differences are realized even when low concentrations of protein are utilized in an application. Furthermore, the benefits imparted by HHP were not diminished by the pasteurization and homogenization that the ice cream mix underwent before freezing. Additional research is recommended to investigate the longterm stability of HHP-treated fresh WPC.

\section{CONCLUSIONS}

High hydrostatic pressure treatment of whey proteins exhibited a positive effect on lowfat ice cream mix overrun and foam stability and lowfat ice cream hardness, demonstrating that HHP affects the acceptability of lowfat ice cream even when HHP-treated whey proteins are used at a concentration as low as $0.82 \%$ TS and $0.3 \%$ protein in a formulation of lowfat ice cream. Significant differences in overrun, foam stability, rheological properties, hardness, and sensory evaluation were observed in ice cream mix and ice cream produced using reconstituted WPC 35 or fresh HHP-treated WSU-WPC. As a result, HHP treatment of fresh WPC may provide benefits for applications requiring foaming properties in the food industry.

\section{ACKNOWLEDGMENTS}

This research was funded by Washington State Dairy Products Commission. Special thanks are given to Foremost Farms and Grain Processing Corporation for supplying ingredients, and Jaydeep Chauhan, Carol Padiernos, Michael Costello, and the WSU Creamery staff for assisting with this research.

\section{REFERENCES}

Aime, D. B., S. D. Arntfield, L. J. Malcolmson, and D. Ryland. 2001. Textural analysis of fat reduced vanilla ice cream products. Food Rev. Int. 34:237-246.

Akoh, C. C. 1998. Fat replacers. Food Technol. 52:47-53.

Cheftel, J. C. 1992. Effects of high hydrostatic pressure on food constituents: An overview. High Pressure Biotechnol. 224:195-209.

Cottrell, J. I. L., G. Pass, and G. O. Phillips. 1980. The effect of stabilizers on the viscosity of an ice cream mix. J. Sci. Food Agric. 31:1066-1070.

Datta, N., and H. C. Deeth. 1999. High-pressure processing of milk and dairy products. Aust. J. Dairy Technol. 54:41-48.

DeVilbiss, E. D., V. H. Holsinger, L. P. Posati, and M. J. Pallansch. 1974. Properties of whey protein concentrate foams. Food Technol. 28:40-48.

deWit, J. N., and G. Klarenbeek. 1984. Effect of various heat treatments on structure and solubility of whey proteins. J. Dairy Sci. 67:2701-2710.

deWit, J. N., G. Klarenbeek, and M. Adamse. 1996. Evaluation of functional properties of whey protein concentrates and whey protein isolates. 2. Effects of processing history and composition. Neth. Milk Dairy J. 40:41-56.

Drewnowski, A. 1992. Sensory properties of fats and fat replacements. Nutr. Rev. 50:17-20.

Flores, A. A., and H. D. Goff. 1999. Ice crystal size distributions in dynamically frozen model solutions and ice cream as affected by stabilizers. J. Dairy Sci. 82:1399-1407.

Galazka, V. B., D. A. Ledward, and J. Varley. 1997. High pressure processing of $\beta$-lactoglobulin and bovine serum albumin. Pages 127-136 in Food colloids: Proteins, lipids and polysaccharides. E. Dickinson, and B. Bergenståhl, ed. The Royal Society of Chemistry, Cambridge, UK.

Garcia, R. S., R. T. Marshall, and H. Heymann. 1995. Lowfat ice creams from freeze-concentrated versus heat-concentrated nonfat milk solids. J. Dairy Sci. 78:2345-2351.

Giese, J. 1996. Fats, oils, and fat replacer. Food Technol. 50:78-83.

Goff, H. D., V. J. Davidson, and E. Cappi. 1994. Viscosity of ice cream mix at pasteurization temperatures. J. Dairy Sci. 77:2207-2213.

Guinard, J. X., C. Zoumas-Morse, L. Mori, D. Panyam, and A. Kilara. 1996. Effect of sugar and fat on the acceptability of vanilla ice cream. J. Dairy Sci. 79:1922-1927.

Harper, J., and M. Mangino. 2007. Food proteins lecture notes: Protein functionality. http://class.fst.ohio-state.edu/FST822/lectures/lect.htm. Ohio State University; Accessed Aug. 15, 2007.

Ibanoglu, E., and S. Karatas. 2001. High pressure effect on foaming behavior of whey protein isolate. J. Food Eng. 47:31-36.

Lee, F. Y., and C. H. White. 1991. Effect of ultrafiltration retentates and whey protein concentrates on ice cream quality during storage. J. Dairy Sci. 74:1170-1180.

Lim, S.-Y., B. G. Swanson, and S. Clark. 2008. High hydrostatic pressure modification of whey protein concentrate for improved functional properties. J. Dairy Sci. 91:1299-1307.

Messens, W., J. Van Camp, and A. Huyghebaert. 1997. The use of high pressure to modify the functionality of food proteins. Trends Food Sci. Technol. 8:107-112.

Morr, C. V., and E. Y. W. Ha. 1993. Whey protein concentrates and isolates: Processing and functional properties. CRC Crit. Rev. Food Sci. Nutr. 33:431-476.

Mussa, D. M., and H. S. Ramaswamy. 1997. Ultra-high-pressure pasteurization of milk: Kinetics of microbial destruction and changes in physico-chemical characteristics. Lebensm. Wiss. Technol. 30:551-557.

Naidu, P. G., T. J. Rao, M. P. Ali, and P. M. Sastri. 1986. Effect of utilization of whey in ice cream. Indian J. Dairy Sci. 39:94-95.

Needs, E. C., M. Capellas, A. P. Bland, P. Manoj, D. MacDougal, and G. Paul. 2000. Comparison of heat and pressure treatments of skim milk, fortified with whey protein concentrate, for set yogurt preparation: effects on milk proteins and gel structure. J. Dairy Res. 67:329-348. 
Ohmes, R. L., R. T. Marshall, and H. Heymann. 1998. Sensory and physical properties of ice creams containing milk fat or fat replacers. J. Dairy Sci. 81:1222-1228.

Penna, A. L. B., S. Gurram, and G. V. Babosa-Cánovas. 2006. Effect of high hydrostatic pressure processing on rheological and textural properties of probiotic low-fat yogurt fermented by different starter cultures. J. Food Process Eng. 29:447-461.

Phillips, L. G., J. B. German, T. E. O'Neill, E. A. Foegeding, V. R. Hanvalkar, A. Kilara, B. A. Lewis, M. E. Mangino, C. V. Morr, J. M. Regenstein, D. M. Smith, and J. E. Kinsella. 1990. Standardized procedure for the measurement of the foaming properties of three proteins: A collaborative study. J. Food Sci. 55:14411444., 1453.

Pridiville, E. A., R. T. Marshall, and H. Heyman. 1999. Effect of milk fat on the sensory properties of chocolate ice cream. J. Dairy Sci. 82:1425-1432.

Richert, S. H., C. V. Morr, and C. M. Cooney. 1974. Effect of heat and other factors upon foaming properties of whey protein concentrates. J. Food Sci. 39:42-48.
Roessler, E. B., R. M. Pangborn, J. L. Sidel, and H. Stone. 1978. Expanded statistical tables for estimating significance in pairedpreference, paired difference, duo-trio and triangle tests. J. Food Sci. 43:940-941.

Roland, A. M., L. G. Phillips, and K. J. Boor. 1999. Effects of fat content on the sensory properties, melting, color, and hardness of ice cream. J. Dairy Sci. 82:32-38.

SAS Institute. 1999. SAS/STAT User's Guide: Version 8.0 ed. SAS Inst., Inc., Cary, NC.

Smith, D. E., A. S. Bakshi, and C. J. Lomauro. 1984. Changes in freezing point and rheological properties of ice cream mix as function of sweetener system and whey substitution. Milchwissenschaft 39:455-457.

Stanley, D. W., H. D. Goff, and A. K. Smith. 1996. Texture-structure relationships in foamed dairy emulsions. Food Rev. Int. 29:1-13.

Yilsay, T. Ö., L. Yilmaz, and A. A. Bayizit. 2006. The effect of using a whey protein fat replacer on textural and sensory characteristics of low-fat vanilla ice cream. Eur. Food Res. Technol. 222:171-175.

Zhu, H., and S. Damodaran. 1994. Heat-induced conformational changes in whey protein isolate and its relation to foaming properties. J. Agric. Food Chem. 42:846-855. 